Journal of Helminthology

cambridge.org/jhl

\section{Research Paper}

Cite this article: Rashidifard M, Bello TT, Fourie H, Coyne DL, Peña-Santiago R (2021). Morphological and molecular characterization of Aporcella femina sp. n. (Dorylaimida, Aporcelaimidae) from Nigeria. Journal of Helminthology 95, e7, 1-8. https://doi.org/ $10.1017 /$ S0022149X20001042

Received: 19 November 2020

Revised: 29 December 2020

Accepted: 30 December 2020

\section{Key words:}

Description; LSU; morphology; morphometry; phylogeny; SSU

Author for correspondence:

M. Rashidifard,

E-mail: milad.rashidifard@nwu.ac.za

\title{
Morphological and molecular characterization of Aporcella femina sp. n. (Dorylaimida, Aporcelaimidae) from Nigeria
}

M. Rashidifard ${ }^{1}$ (D), T.T. Bello ${ }^{1,2}$, H. Fourie ${ }^{1}$, D.L. Coyne ${ }^{2}$ and R. Peña-Santiago ${ }^{3}$

${ }^{1}$ Unit for Environmental Sciences and Management, North-West University, Private Bag X6001, Potchefstroom 2520, South Africa; ${ }^{2}$ International Institute of Tropical Agriculture, IITA, PMB 5320, Ibadan, Nigeria and

${ }^{3}$ Departamento de Biología Animal, Biología Vegetal y Ecología, Universidad de Jaén,Campus 'Las Lagunillas’ s/n, Edificio B3, Jaén 23071, Spain

\begin{abstract}
A new species of the genus Aporcella collected from a watermelon field in Nigeria is described, including its morphological and molecular (small subunit (SSU) and large subunit (LSU) ribosomal DNA (rDNA)) characterization. Aporcella femina sp. $\mathrm{n}$. is distinguished by its 3.21-3.64 mm-long body, inner cuticle layer with fine but distinct transverse striation, lip region offset by deep constriction, $22-25 \mu \mathrm{m}$ broad, odontostyle $20-26 \mu \mathrm{m}$, neck $661-811 \mu \mathrm{m}$ long, pharyngeal expansion occupying $52-56 \%$ of the total neck length, female genital system didelphic-amphidelphic, uterus $191-350 \mu \mathrm{m}$ or $1.9-3.3$ mid-body diameters long, $V=52-57$, tail short and convex conoid $\left(35-48 \mu \mathrm{m}, c=72-98, \quad c^{\prime}=0.7-0.9\right)$ and males absent. Phylogenetic analyses based on the partial sequence of SSU and LSU (D2-D3) rDNA revealed a close relationship of A. femina sp. n. with other Aporcella species, confirming the monophyly of the genus as well as its association to a clade made of several taxa characterized by the absence of pars refringens vaginae.
\end{abstract}

\section{Introduction}

The genus Aporcella Andrássy, 2002 is a widely distributed dorylaimid (Dorylaimida) taxon, inhabiting soils of all zoogeographical realms/regions except Antarctica (Álvarez-Ortega et al., 2013; Vazifeh et al., 2020). In Africa, it occurs in the southern part of the continent (Botswana and South Africa), where four species have so far been recorded: Aporcella adriaani (Botha \& Heyns, 1990) Álvarez-Ortega, Subbotin \& Peña-Santiago, 2013; Aporcella debruinae ÁlvarezOrtega, Subbotin \& Peña-Santiago, 2013; Aporcella parapapillata (Botha \& Heyns, 1990) Andrássy, 2009; and Aporcella tropica (Jana \& Baqri, 1981) Álvarez-Ortega, Subbotin \& Peña-Santiago, 2013.

Since its original description by Andrássy (2002), the taxonomy of Aporcella has been subjected to a number of changes, including a new definition (Álvarez-Ortega et al., 2013), the description of new species (Andrássy, 2012; Álvarez-Ortega \& Peña-Santiago, 2016; Naghavi et al., 2019, 2020) and a recent update of its taxonomy (Vazifeh et al., 2020). Molecular analyses have repeatedly supported the monophyly of Aporcella. Surprisingly, the closer evolutionary relationship of Aporcella with non-aporcelaimid taxa (tylencholaims, discolaims) than with other aporcelaims has also been reported by various researchers (Álvarez-Ortega \& Peña-Santiago, 2016; Imran et al., 2019; Naghavi et al., 2019; Vazifeh et al., 2020).

From a 2016 survey of nematode fauna associated with watermelon in Nigeria, specimens of an Aporcella population that belong to an undescribed species were recovered. This would represent a novel geographical record for the genus, and, by means of its molecular analysis, offers the chance to confirm previous findings about its monophyly and phylogeny.

\section{Materials and methods}

\section{Extraction and processing of nematodes}

Nematode specimens were recovered from rhizosphere soil samples that were collected from watermelon fields in south-west Nigeria during 2016. Extraction of nematodes from soil followed a modified pie pan method (Coyne et al., 2007). Nematodes were fixed in a hot $4 \%$ formaldehyde solution for morphological observations (Nico et al., 2002) and subsequently mounted in anhydrous glycerine as permanent slides (De Grisse, 1963), while others were stored in dimethyl sulphoxide, disodium ethylenediamine tetra-acetic acid and saturated sodium chloride (abbreviated here as DESS) solution for molecular analysis. Morphological features of nematodes were observed, measured and photographed using an Eclipse 80i 
M. Rashidifard et al.

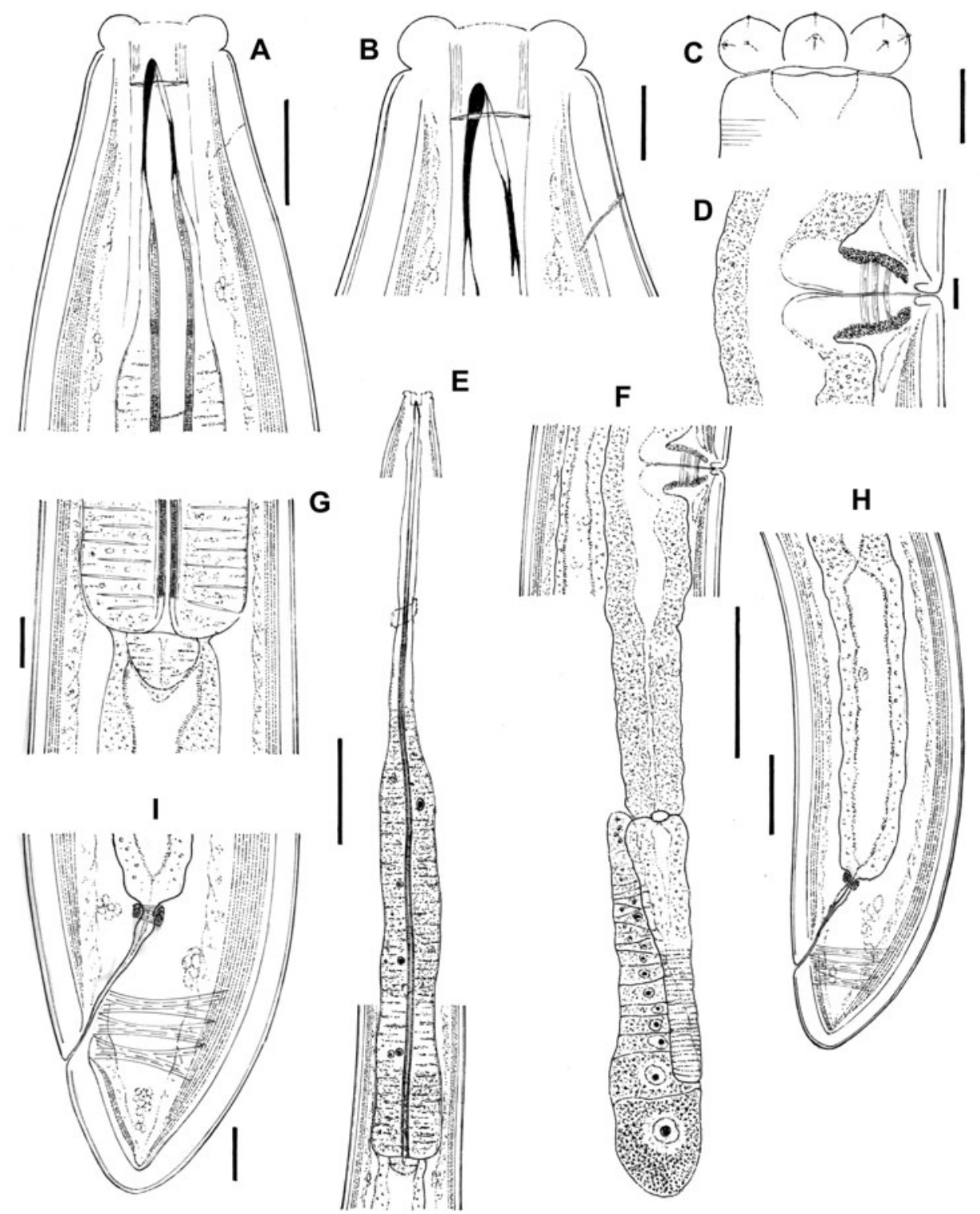

Fig. 1. Aporcella femina sp. $n$. (female): (a, b) anterior region in lateral median view; (c) anterior region in lateral surface view; (d) vagina region; (e) neck region; (f) posterior genital branch; (g) pharyngo-intestinal junction; (h) posterior body region; (i) caudal region. Scale bars: (a, g, i) $20 \mu \mathrm{m}$; (b-d) $10 \mu \mathrm{m}$; (e, f) $100 \mu \mathrm{m}$; (h) $50 \mu \mathrm{m}$.

microscope (Nikon, Tokyo, Japan) equipped with differential interference contrast optics, a drawing tube (camera lucida) and a DS digital camera (Nikon, Tokyo, Japan).

\section{Molecular identification}

Fixed specimens in DESS were rinsed using double-distilled water, and two specimens were transferred to individual $1.5 \mathrm{ml}$ tubes containing $15 \mu \mathrm{l}$ nuclease-free water. DNA were extracted using chelex-100 by adding $20 \mu \mathrm{l}$ of chelex $(5 \% \mathrm{w} / \mathrm{v})$ and $5 \mu$ proteinase $\mathrm{K}$ to each tube, followed by incubation at $57^{\circ} \mathrm{C}$ for $120 \mathrm{~min}$ and at $95^{\circ} \mathrm{C}$ for $10 \mathrm{~min}$ (Rashidifard et al., 2019).

DNA amplification was carried out on a Vacutec thermocycler (www.vacutec.co.za) using the primers: small subunit (SSU) F04 (5'-GCTTGTCTCAAAGATTAAGCC-3'), and SSU R26 (5'-CATTCTTGGCAAATGCTTTCG-3') (Blaxter et al., 1998) for
SSU ribosomal DNA (rDNA), as well as D2A (5'-ACAAGTA CCGTGAGGGAAAGTTG-3') and D3B (5'-TCGGAAGGAA CCAGCTACTA-3') (Subbotin et al., 2006) for D2-D3 large subunit (LSU) rDNA. The polymerase chain reaction (PCR) amplification process was followed as reported by Rashidifard et al. (2020). Four microliters of PCR products were loaded on $1 \%$ agarose gel and visualized by an ultraviolet transilluminator to check the quality of DNA. The DNA was sequenced in both forward and reverse directions by the Inqaba Biotec ${ }^{\mathrm{TM}}$ genomic company (South Africa; www.inqaba-southafrica.co.za).

\section{Phylogenetic analyses}

The new SSU and LSU sequences obtained for the new species were compared to other available sequences in the GenBank using the BLASTN search tool. One data set was prepared for 

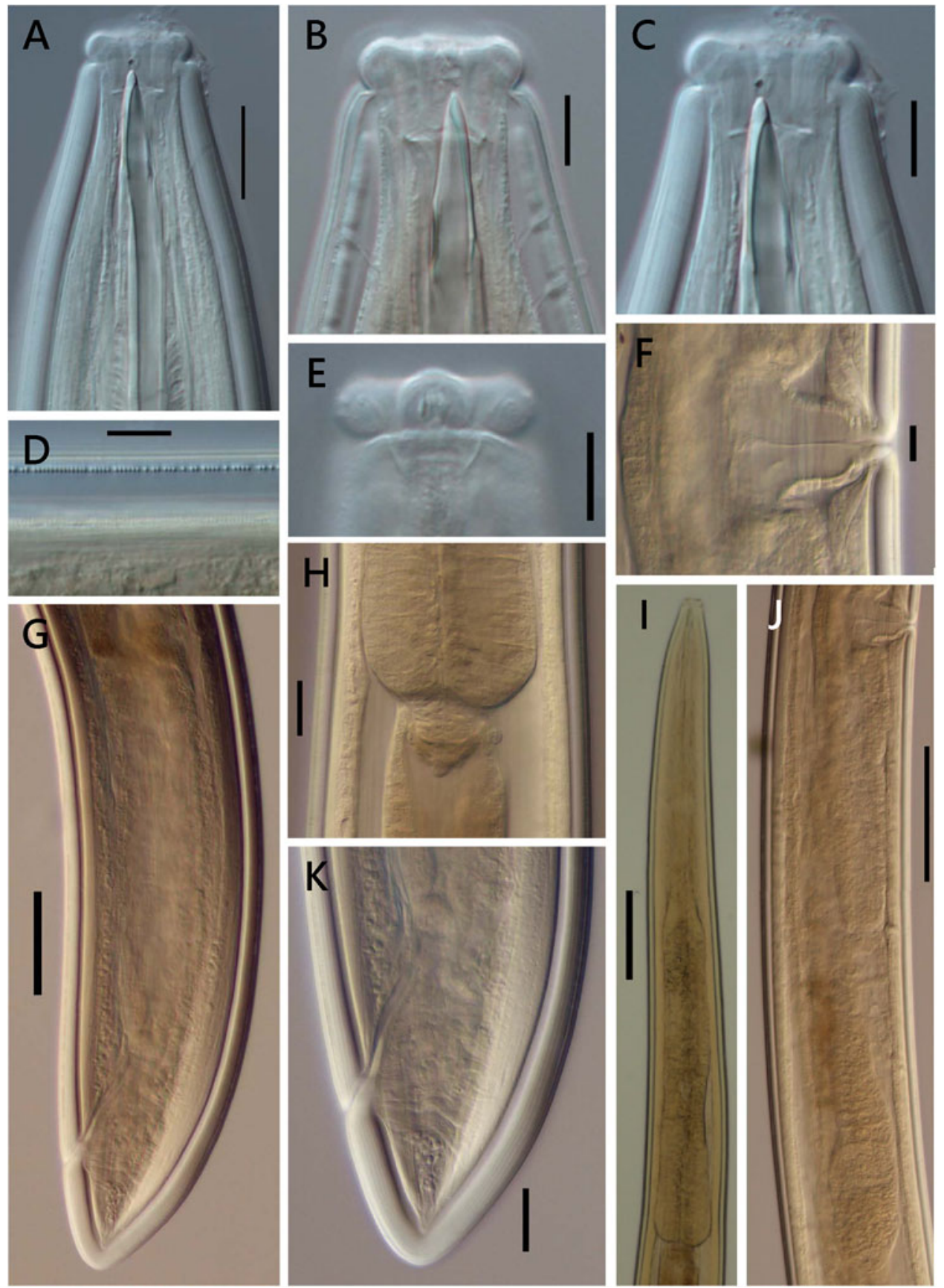

Fig. 2. Aporcella femina sp. $n$. (female: light microscopy): (a-c) anterior region in lateral median view; (d) cuticle; (e) anterior region in lateral surface view; (f) vagina region; (g) posterior body region; (h) pharyngo-intestinal junction; (i) neck region; (j) posterior genital branch; (k) caudal region. Scale bars: (a, h, k) $20 \mu \mathrm{m}$; (b-f) $10 \mu \mathrm{m}$; (g) $50 \mu \mathrm{m} ;(\mathrm{i}, \mathrm{j}) 100 \mu \mathrm{m}$.

each of the SSU and LSU regions and taxa selection was carried out according to Rashidifard et al. (2020). The available sequences as well as outgroups in the SSU data set were aligned using the MUSCLE alignment tool (Edgar, 2004) in Geneious Prime ${ }^{\infty}$ 2020.2.3 (www.geneious.com), while the LSU data set was aligned using the E-INS-I algorithm in the MAFF alignment tool (Katoh \& Standley, 2013). According to the jModeTest 2.1.10 (Darriba et al., 2012), the Hasegawa-Kishino-Yano with a gamma distribution $(\mathrm{HKY}+\mathrm{G})$ was the best substitution model for the SSU dataset. However, the General Time Reversible with proportion of invariable sites and a gamma distribution $(\mathrm{GTR}+\mathrm{I}+\mathrm{G})$ was selected as the most appropriate model for the LSU dataset.

Bayesian inference was conducted in MrBayes v3.1.2 (Ronquist \& Huelsenbeck, 2003) implemented in Geneious Prime ${ }^{\varpi}$ 2020.2.3 (www.geneious.com). The chain was running $3 \times 10^{6}$ generations for both the SSU and LSU data sets, and after discarding the $25 \%$ burn-in samples, the remaining samples were used for further analyses. The Markov chain Monte Carlo (MCMC) algorithm was implemented to calculate the posterior probabilities (PB) for each of the phylogenetic trees (Larget \& Simon, 1999) 


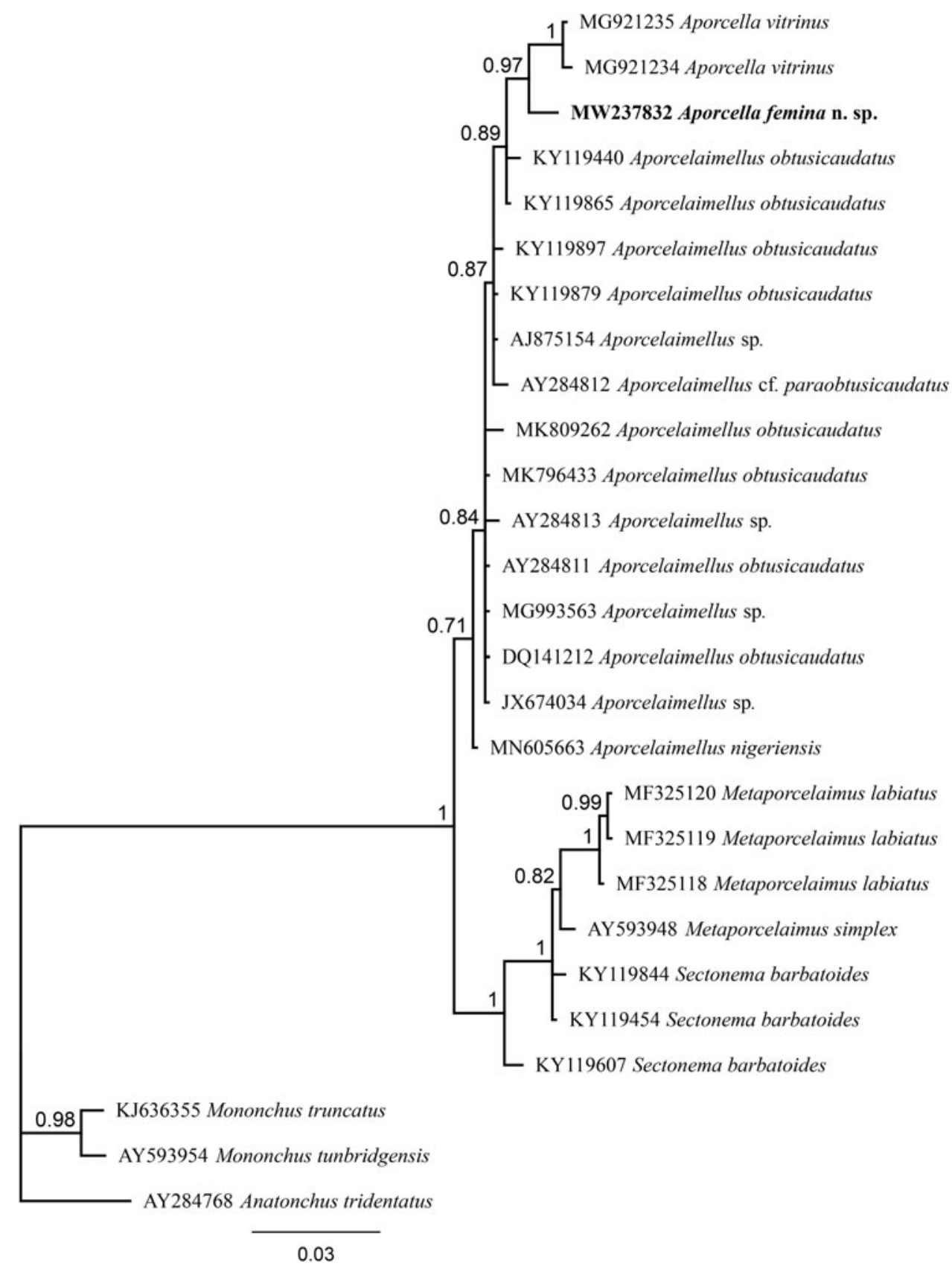

Fig. 3. Bayesian tree with $50 \%$ majority rule of Aporcella femina $\mathrm{n}$. sp. from Nigeria using partial SSU rDNA sequences under the HKY $+\mathrm{G}$ model. The sequence of new species is indicated by bold font. Scale bar shows the number of substitution per site.

using the $50 \%$ majority rule. The mononchid taxa were used as outgroups for both the SSU and LSU phylogenies.

\section{Results}

\section{Aporcella femina sp. $\mathrm{n}$.}

\section{Material examined}

Ten females in variable but generally good state of preservation (figs 1-3).

\section{Measurements}

All measurements are presented in table 1.

\section{Description}

Female. Moderately to slender $(a=28-38)$ nematodes of large size, 3.21-3.64 mm long. Body cylindrical, tapering towards both ends but substantially towards the anterior region, while the tail is short and rounded. Upon fixation, habitus regularly curved ventrad, C- to G-shaped. Cuticle two-layered, very thick throughout the entire body, $4-7 \mu \mathrm{m}$ in anterior region, 7.5$9.5 \mu \mathrm{m}$ at mid-body and $7.5-11.5 \mu \mathrm{m}$ on tail, consisting of a thin outer layer with nearly smooth surface, and a thicker inner layer that displays a fine but distinct transverse striation (fig. $2 \mathrm{~g})$. Lateral chords narrow, $6-17 \mu \mathrm{m}$ wide or $6-19 \%$ of mid-body diameter. Ventral and dorsal pores restricted to cervical region, two or three in number at each side at odontostyle-odontophore 
Table 1. Morphometrics of Aporcella femina sp. $\mathrm{n}$. from Nigeria and two other African species of the genus.

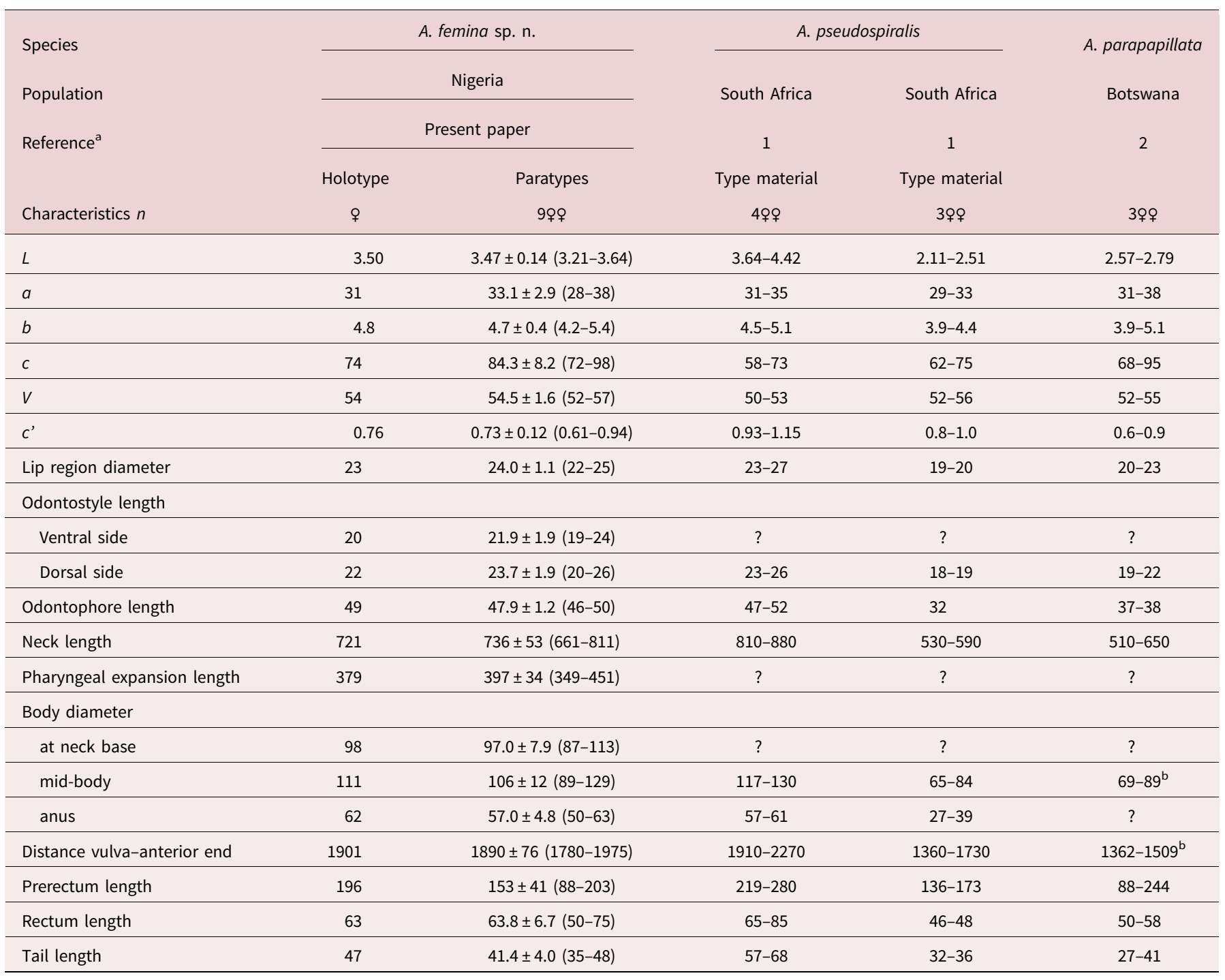

Measurements in $\mu \mathrm{m}$ except $L$ in $\mathrm{mm}$, and in the form average \pm standard deviation (range).

${ }^{a}$ 1: Botha \& Heyns (1990); 2: De Bruin \& Heyns (1992).

${ }^{\mathrm{b}}$ Calculated from other morphometrics.

level; lateral pores small. Lip region offset by a distinct constriction, 3.3-3.8 times wider than high and less than one-third $(22-29 \%)$ of body diameter at neck base; lips separate, with moderately protruding papillae. Amphidial fovea stirrup-shaped, its opening $9-10.5 \mu \mathrm{m}$, less than one-half $(38-46 \%)$ of lip region diameter. Cheilostom broad, 10.5-14 $\mu \mathrm{m}$ long, with thick walls. Odontostyle strong, 3.8-4.3 times longer than wide, barely shorter (0.9-1.0 times) than lip region diameter and $0.58-0.73 \%$ of total body length, with aperture $13-17 \mu \mathrm{m}$ long or $c$. two-thirds (58$76 \%)$ of total length. Guiding ring simple but distinct, plicate. Odontophore linear, rod-like, 1.9-2.4 times longer than odontostyle. Pharynx entirely muscular, enlarging very gradually, with its basal expansion 5.8-9.0 times as long as wide, 3.1-4.5 times the body diameter at neck base and occupying $52-56 \%$ of total neck length; pharyngeal gland nuclei located as follows $(n=1)$ : $\mathrm{DO}=47-52, \mathrm{DN}=48-56, \mathrm{DO}-\mathrm{DN}=3-5, \mathrm{~S}_{1} \mathrm{~N}_{1}=61-66, \mathrm{~S}_{1} \mathrm{~N}_{2}=$ $73-75, \mathrm{~S}_{2} \mathrm{~N}=85-88$. Cardia short and rounded conoid, $21-32 \times$ 20-34 $\mu \mathrm{m}$, surrounded by intestinal tissue that forms a short extension projection into the intestinal lumen. Genital system didelphic-amphidelphic, with well-developed genital branches, the anterior $346-565 \mu \mathrm{m}$ or $11-15 \%$ of body length, the posterior $381-638 \mu \mathrm{m}$ or $12-18 \%$ of body length. Ovaries comparatively small, mostly not reaching the oviduct-uterus junction, the anterior $103-259 \mu \mathrm{m}$ and posterior 106-231 $\mu \mathrm{m}$ long. Anterior oviduct $127-200 \mu \mathrm{m}$ or $1.4-1.8$ body diameters long, posterior oviduct 133-203 $\mu \mathrm{m}$ or $1.4-1.9$ body diameters long, both consisting of a slender distal portion made of prismatic cells and a distinct pars dilatata with perceptible lumen. Oviduct and uterus separated by a distinct sphincter. Anterior uterus $191-325 \mu \mathrm{m}$ or 1.9-3.1 body diameters long, posterior uterus $204-350 \mu \mathrm{m}$ or 2.1-3.3 body diameters long, often appearing as a simple, tubelike structure, but with some (well-preserved) specimens having a longer uterus, which enables the appreciation of a wider proximal uterine region and a more slender distal region, both of about similar length. No uterine egg observed. Vagina extending inwards $40-54 \mu \mathrm{m}$, occupying $c$. one-half (41-45\%) of body diameter: pars proximalis $28-41 \times 19-28 \mu \mathrm{m}$, with distally convergent walls and surrounded by a relatively weak musculature; pars 


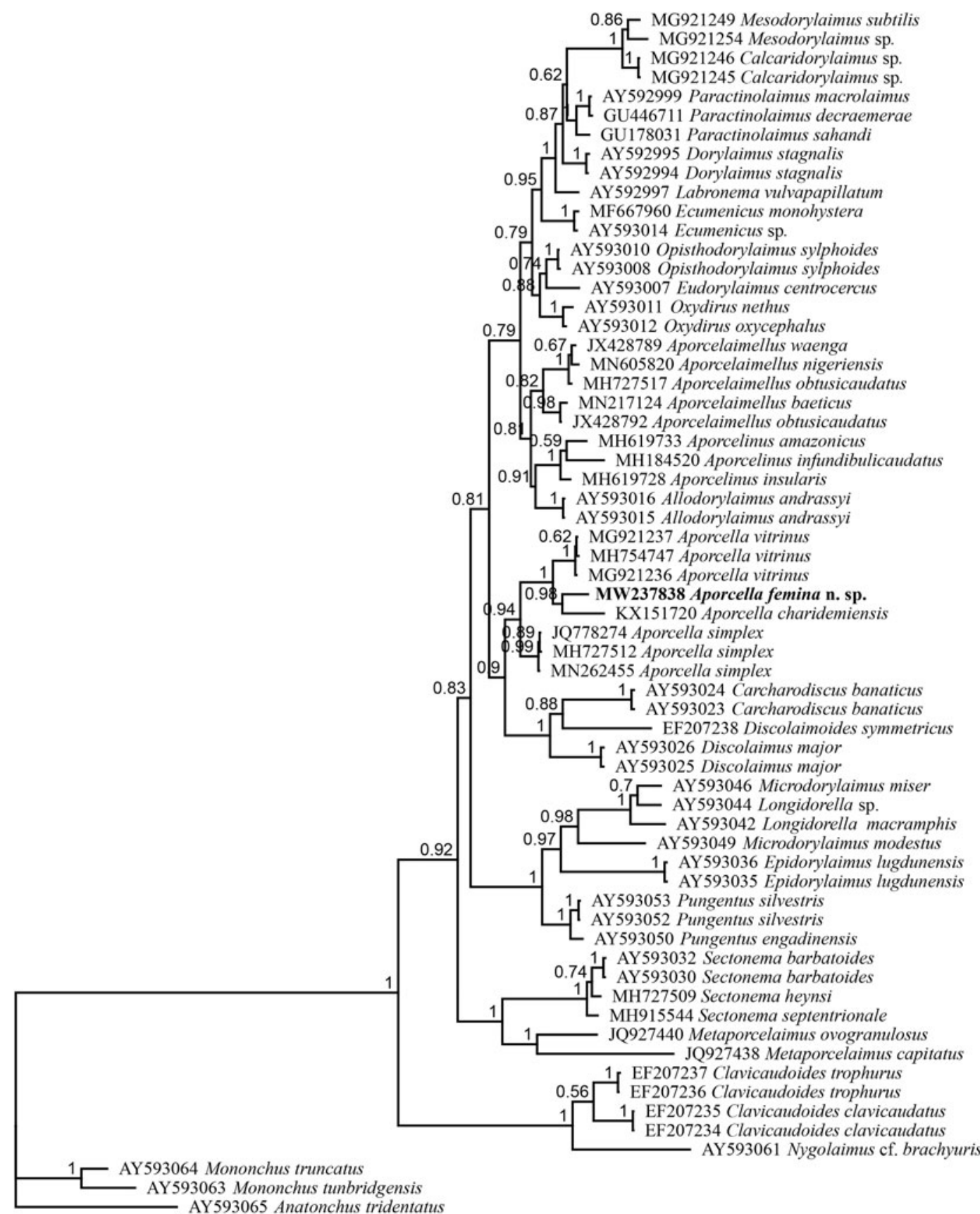

0.2

Fig. 4. Bayesian tree with $50 \%$ majority rule of Aporcella femina $n$. sp. from Nigeria using partial LSU (D2-D3) rDNA sequences under the GTR $+I+G$ model. The sequence of new species is indicated by bold font. Scale bar shows the number of substitutions per site.

distalis well-developed, 10-14 $\mu \mathrm{m}$ long; pars refringens absent. Vulva a slightly posterior transverse slit. Prerectum $2.4-4.0$, rectum $0.8-1.5$ times the anal body diameter long. Tail short, convex conoid, its ventral side weakly straighter than the dorsal side; caudal pores two pairs, close together, at the posterior half of tail, one lateral, another sublateral.

Male. Unknown. Females do not contain sperm cells.

Type locality and habitat

South-west Nigeria, Odeda $\left(7^{\circ} 10^{\prime} 59.999^{\prime \prime} \mathrm{N}, 3^{\circ} 26^{\prime} 42.01^{\prime \prime} \mathrm{E}\right)$, an agrarian locality with a history of cassava (Manihot esculenta Crantz) and vegetable production; specimens were collected from a field cultivated with watermelon (Citrullus lanatus) on sandy-loam soil ( sand $=66 \%$, silt $=13 \%$, clay $=21 \%$, organic matter $=11.18 \%, \mathrm{pH}$ 6.22).

\section{Molecular characterization}

After sequencing and editing, two totally (100\%) identical sequences per each locus (SSU and LSU) were obtained; therefore, only one sequence was used for analysis and deposited into the NCBI GenBank: a 745 bp-long LSU sequence (accession number MW237838) and another 855 bp-long SSU sequence (accession 
number MW237832). The evolutionary relationships of the new species are presented in figs 3 and 4.

\section{Type material}

Female holotype and nine female paratypes, deposited in the nematode collection of the University of Jaén, Spain.

\section{Etymology}

The specific epithet is a Latin term meaning woman or female, and refers to the existence of only females in this species.

\section{Diagnosis and relationships}

The new species is characterized by its $3.21-3.64 \mathrm{~mm}$-long body, inner cuticle layer with fine but distinct transverse striation, lip region offset by deep constriction and $22-25 \mu \mathrm{m}$ broad, odontostyle $20-26 \mu \mathrm{m}$ at its dorsal side and 19-24 $\mu \mathrm{m}$ at its ventral side, neck 661-811 $\mu \mathrm{m}$ long, pharyngeal expansion $349-451 \mu \mathrm{m}$ long or $52-56 \%$ of total neck length, female genital system didelphic-amphidelphic, uterus $191-350 \mu \mathrm{m}$ or $1.9-3.3$ body diameters long, $V=52-57$, tail short and convex conoid (35-48 $\mu \mathrm{m}$, $\left.c=72-98, c^{\prime}=0.7-0.9\right)$ and males absent.

In having a comparatively long body (more than $3.0 \mathrm{~mm}$ long), Aporcella femina sp. n. resembles Aporcella magna Andrássy, 2012 and Aporcella pseudospiralis (Botha \& Heyns, 1990) Andrássy, 2012, and significantly differs from its other congeners (body 3.21-3.64 vs up to $3.08 \mathrm{~mm}$ long) (see compendium by Álvarez-Ortega et al., 2013 and Vazifeh et al., 2020). It can be distinguished from A. magna, a species occurring in Chile, in its smaller general size: body $3.21-3.64$ versus $4.48-5.00 \mathrm{~mm}$ long, $n=5$; neck $661-811$ versus $888-1020 \mu \mathrm{m}$ long; tail $35-48$ versus $50-60 \mu \mathrm{m}$. It is also smaller than A. pseudospiralis, which is only known to occur in South Africa, with a smaller general size (body $3.21-3.64$ vs $3.64-4.42 \mathrm{~mm}$ long, $n=4$; neck $661-811$ vs $810-880 \mu \mathrm{m}$ long), shorter prerectum $(122-203$ vs 219 $280 \mu \mathrm{m}$ ) and female tail ( $35-48$ vs $57-68 \mu \mathrm{m}, c=72-98$ vs $58-$ $73, c^{\prime}=0.61-0.94$ vs $0.93-1.15$ ) and male absent (vs present).

Among the small-sized Aporcella species (body up to $3.08 \mathrm{~mm}$ long), and due to the comparatively long odontostyle $(>16 \mu \mathrm{m})$, short ( $c^{\prime}$ up to 1.1) and convex conoid tail, it is similar to Aporcella papillata (Bastian, 1865) Álvarez-Ortega, Subbotin \& Peña-Santiago, 2013 and A. parapapillata (Botha \& Heyns, 1990) Andrássy, 2009. The new species differs from A. papillata, currently recorded from UK only (Thorne \& Swanger, 1936; Álvarez-Ortega \& Peña-Santiago, 2010), in its larger general size (body $3.21-3.64$ vs $2.43-3.08 \mathrm{~mm}$ long; neck $661-811$ vs $510-$ $650 \mu \mathrm{m}$ long), longer uterus (191-350 vs $111-131 \mu \mathrm{m}$ or $1.9-$ 3.3 vs $1.3-1.5$ body diameters long), more posterior vulva ( $V=$ $52-57$ vs $V=45-50, n=11$ ) and male absent (vs present); and from A. parapapillata, recorded from South Africa (Botha \& Heyns, 1990; De Bruin \& Heyns, 1992), in its larger general size (body $3.21-3.64$ vs $2.11-2.79 \mathrm{~mm}$ long; neck $661-811$ vs $555-649 \mu \mathrm{m}$ long), much longer odontophore (44-50 vs 26$38 \mu \mathrm{m}, n=12$ ) and male absent (vs as frequent as female).

The new species described herein displays intermediate morphometrics between two South African species - namely, A. parapapillata and A. pseudospiralis - all of them described based on relatively few specimens. Aporcella femina sp. n. is very similar to A. pseudospiralis, but, as mentioned above, they differ in their overall size and especially in tail length. Therefore, the possibility of co-specificity could be raised, and the noted differences possibly due to geographical variations. The absence of molecular data for A. parapapillata and $A$. pseudospiralis currently prevents any molecular comparison, which, when available, would clarify any ambiguity. However, the available morphological information clearly distinguishes the three species from each other, supporting a separate status for them.

The evolutionary relations of the new species, as derived from the molecular analyses based on the partial sequence of SSU and LSU rDNA, are represented in figs 3 and 4. According to the SSU phylogeny, the new species is in a highly supported (BPP: 97\%) sister relation with Aporcella vitrinus. Furthermore, Bayesian tree using partial LSU sequence shows that the new species forms part of a fully supported (BPP: 100\%) subclade with Aporcella charidemiensis and A. vitrinus, the former being the closest relative, which is recorded from Spain. A highly supported (BPP: 94\%) Aporcella clade is made of this subclade along with three Aporcella sequences belonging to A. simplex. Therefore, the present results confirm previous findings (for instance, see Naghavi et al., 2019; Vazifeh et al., 2020) about both the monophyly of Aporcella, and the belonging of Aporcella sequences to a large clade morphologically characterized by the absence of pars refringens vaginae, which also includes discolaims in the tree provided herein.

Financial support. One author (R.P.S.) is grateful for the financial support received from the scientific project (ref.: Action 1-PAIUJA 2019-2020: EIRNM02-2017), University of Jaén. Infrastructure and partial funding by the Nematology Unit at North-West University of South Africa is also acknowledged.

\section{Conflicts of interest. None.}

Author contributions.

M.R. and T.T.B. contributed equally.

\section{References}

Álvarez-Ortega S and Peña-Santiago R (2010) Studies on the genus Aporcelaimellus Heyns, 1965 (Dorylaimida: Aporcelaimidae) - material studied by Thorne and Swanger in 1936 but not named. Russian Journal of Nematology 18, 69-84.

Álvarez-Ortega S and Peña-Santiago R (2016) Aporcella charidemiensis sp. n. (Dorylaimida: Aporcelaimidae) from the southern Iberian Peninsula, with comments on the phylogeny of the genus. Nematology 18, 811-821.

Álvarez-Ortega S, Subbotin SA and Peña-Santiago R (2013) Morphological and molecular characterisation of Aporcelaimellus simplex (Thorne \& Swanger, 1936) Loof \& Coomans, 1970 and a new concept for Aporcella Andrássy, 2002 (Dorylaimida: Aporcelaimidae). Nematology 15, 165-178.

Andrássy I (2002) New genera and species of nematodes from southern Chile. Opuscula Zoologica Budapestensis 34, 5-22.

Andrássy I (2012) Two new species of the family Aporcelaimidae (Nematoda. Dorylaimida). Genus 23, 189-199.

Blaxter ML, De Ley P, Garey JR, et al. (1998) A molecular evolutionary framework for the phylum Nematoda. Nature 392, 71-75.

Botha A and Heyns J (1990) Aporcelaimidae (Nematoda: Dorylaimida) from the Kruger National Park. Koedoe 33, 27-46.

Coyne DL, Nicol JM and Claudius-Cole B (2007) Practical plant nematology: a field and laboratory guide. SP-IPM Secretariat, Cotonou, Benin. International Institute of Tropical Agriculture (IITA).

Darriba D, Taboada GL, Doallo R and Posada D (2012) Jmodeltest 2: more models, new heuristics and parallel computing. Nature Methods 9, 772.

De Bruin S and Heyns J (1992) Dorylaimida (Nematoda) from Bostwana. South African Journal of Zoology 27, 156-172.

De Grisse A (1963) A counting dish for nematodes excluding border effect. Nematologica 9, 162.

Edgar RC (2004) MUSCLE: multiple sequence alignment with high accuracy and high throughput. Nucleic Acids Research 32, 1792-1797.

Imran Z, Abolafia J, Peña-Santiago R and Ahmad W (2019) Morphological and molecular characterisation of Moshajia idiofora Siddiqi, 1982 
(Dorylaimida: Qudsianematidae), with new insights into the phylogeny of the enigmatic Lordellonematinae. Nematology 21, 349-360.

Katoh K and Standley DM (2013) MAFFT multiple sequence alignment software version 7: improvements in performance and usability. Molecular Biology and Evolution 30, 772-780.

Larget B and Simon DL (1999) Markov chain Monte Carlo algorithms for the Bayesian analysis of phylogenetic trees. Molecular Biology and Evolution 16, 750-759.

Naghavi A, Niknam G, Vazifeh N and Peña-Santiago R (2019) Morphological and molecular characterisation of two species of Aporcella Andrássy, 2002 (Nematoda: Dorylaimida: Aporcelaimidae) from Iran, with new insights into the phylogeny of the genus. Nematology 21, 665-665.

Naghavi A, Niknam G, Vazifeh N and Peña-Santiago R (2020) Study of two species, one new and one known, of the genus Aporcella Andrássy, 2002 (Dorylaimida, Aporcelaimidae) from Iran, with a note on its phylogeny. Journal of Helminthology 94, e164.

Nico AI, Rapoport HF, Jiménez-Díaz RM and Castillo P (2002) Incidence and population density of plant-parasitic nematodes associated with olive planting stocks at nurseries in southern Spain. Plant Disease 86, 1075-1079.
Rashidifard M, Marais M, Daneel MS, Mienie CMS and Fourie H (2019) Molecular characterisation of Meloidogyne enterolobii and other Meloidogyne spp. from South Africa. Tropical Plant Pathology 44, 213-224.

Rashidifard M, Bello TT, Fourie H, Coyne DL and Peña-Santiago R (2020) Morphological and molecular characterisation of Aporcelaimellus nigeriensis sp. n. (Dorylaimida: Aporcelaimidae), a remarkable dorylaim from Nigeria. Nematology 22, 867-877.

Ronquist F and Huelsenbeck JP (2003) MrBayes 3: Bayesian phylogenetic inference under mixed models. Bioinformatics 19, 1572-1574.

Subbotin SA, Sturhan D, Chizhov VN, Vovlas N and Baldwin JG (2006) Hylogenetic analysis of Tylenchida Thorne, 1949 as inferred from D2 and D3 expansion fragments of the 28S rRNA gene sequences. Nematology 8, 455-474.

Thorne G and Swanger HH (1936) A monograph of the nematode genera Dorylaimus Dujardin, Aporcelaimus n. gen., Dorylaimoides n. gen., and Pungentus n. gen. Capita Zoologica 6, 1-223.

Vazifeh N, Niknam G, Naghavi A, Jabbari $H$ and Peña-Santiago $R$ (2020) Description of Aporcella minor sp. n. (Dorylaimida: Aporcelaimidae) from Iran, with an updated taxonomy of the genus. Nematology 23, 1-12. 